\title{
Identification of gaps in the current allergic rhinitis guidelines and how these can be filled
}

\author{
Jean Bousquet ${ }^{1}$, Claus Bachert ${ }^{2 *}$, Ralph Mösges ${ }^{3}$, Wytske Fokkens ${ }^{4}$, Peter Hellings ${ }^{5}$ \\ From The 10th Symposium of Experimental Rhinology and Immunology of the Nose (SERIN 2015) \\ Stockholm, Sweden. 19-21 February 2015
}

Currently, there are gaps in the allergic rhinitis (AR) guidelines (and the evidence upon which they are based) that impede their function. Firstly, there is a scarcity of high quality evidence supporting AR treatment decisions [1]. Randomized controlled trials (RCTs) often fail to compare active treatments and use endpoints that are regulatory (not patient) driven. Secondly, a common AR control language for both patients and physicians and a common concept of AR control is missing. Finally, to date, the guidelines do not draw on evidence from real-life studies. These are important as they determine the effects of treatment under the usual conditions of care, thus maximizing applicability of findings to everyday practice. Many of these gaps are currently being filled. Firstly, the efficacy and safety of MP29-02* (a novel intranasal formulation of azelastine hydrochloride and fluticasone propionate in an advanced delivery system) has been shown versus active comparators in large, good quality, RCTs [2,3]. MP2902 *'s superiority over currently considered gold standard therapy (INS) was assessed using more clinically-relevant efficacy endpoints, defining treatment response in a way that is understandable and relevant to patients and health care providers, helping to explain why current first-line therapy often provides sub-optimal symptom relief. Secondly, a simple visual analog scale (VAS) has recently been proposed by MACVIA-LR ARIA as the control language of AR. This will form the basis for the new AR guidelines as part of an integrated care pathway (ICP) [4]. This VAS is also an integral component of a new app called Allergy Diary, designed to assess and track disease control. AR control has been categorized using VAS cutoff scores as 'well-, partly- and un-controlled'. Finally, reallife studies are slowly gaining acceptance. One such study recently showed effective and rapid symptom control by
MP29-02* in AR patients in real-life, using the same VAS score advocated in the ICP. Filling these gaps will ensure that treatment decisions are clinically relevant, encourage simplification of and compliance with AR management guidelines, ensure open and effective communication between all stakeholders and facilitate tailoring of AR medication to patients' needs.

"Dymista

\section{Authors' details}

'University Hospital of Montpellier, MACVIA-LR, EIP on Active \& Health Ageing Ref Site, Montpellier, France. ${ }^{2}$ University Hospital Ghent, Department of Oto-Rhinolaryngology, Ghent, Belgium. ${ }^{3}$ University of Cologne, IMSIE, Cologne, Germany. ${ }^{4}$ Academic Medical Center, Department of Otorhinolaryngology, Amsterdam, Netherlands. ${ }^{5}$ University Hospitals Leuven, Dept of Otorhinolaryngology, Head \& Neck Surgery, Leuven, Belgium.

Published: 26 June 2015

\section{References}

1. Brozek JL, Bousquet J, Baena-Cagnani CE, Bonini S, Canonica GW, Casale TB, et al: Allergic Rhinitis and its Impact on Asthma (ARIA) guidelines: 2010 revision.. JACI 2010, 126(3):466-476.

2. Carr W, Bernstein P, Lieberman, Meltzer E, Bachert C, Price D, et al: A novel intranasal therapy of azelastine with fluticasone for the treatment of allergic rhinitis.. JACl 2012, 129(5):1282-1289.

3. Meltzer E, Ratner P, Bachert C, Carr W, Berger W, Canonica GW, et al: Clinically relevant effect of a new intranasal therapy (MP29-02) in allergic rhinitis assessed by responder analysis.. Int Arch Allergy Immunol 2013, 161(4):369-377.

4. Bousquet J, Addis A, Adcock I, Agache I, Agusti A, Alonso A, et al: Integrated care pathways for airway diseases (AIRWAYS-ICPs). ERJ 2014, 44(2):304-323.

doi:10.1186/2045-7022-5-S4-P39

Cite this article as: Bousquet et al:. Identification of gaps in the current allergic rhinitis guidelines and how these can be filled. Clinical and Translational Allergy 2015 5(Suppl 4):P39. 